\title{
Cultivating Students' Ability to Self-learning in Higher Mathematics Teaching
}

\author{
Hou Lijuan \\ Taishan University, Tai'an, Shandong, 271000, China
}

\begin{abstract}
Under the background of the era of knowledge economy, the information society is in the process of development, and the speed of knowledge renewal is also accelerated.Here, it is of great significance to cultivate college students' autonomous learning ability and innovation ability. In the process of higher mathematics teaching, it is necessary to arouse students' initiative in learning and make them have a correct view of learning. In order to improve the students' learning ability and mathematics comprehensive literacy. This paper makes relevant research on this.
\end{abstract}

Keywords: Higher Mathematics Teaching; Autonomous Learning; Cultivation

Higher mathematics is a basic theory course, which has long been concerned by colleges and universities. There are many problems in students' study, which are usually reflected in teaching. The mode of examination-oriented education has been deeply rooted in the concept of students, so college students' acquisition of knowledge is slack, lack of independent consciousness, and confused about the future development direction.It is mainly reflected in: strong dependence on learning, no enthusiasm for learning, no ability to analyze and deal with problems independently, and many factors can not master the correct learning methods. Teachers need to pay attention to it and seek solutions to improve students' ability to learn independently.

\section{Problems in Higher Mathematics Learning}

https://doi.org/10.47852/bonviewCETR2020010218

This is an open access article published by the BON VIEW PUBLISHING PTE. under the Creative Commons Attributions License. 


\section{A. Students are not interested in learning}

In the current higher mathematics teaching process, because colleges and universities expand enrollment, resulting in a class of arts and science students to take into account the situation. This results in great differences in students' mathematical ability, especially in higher mathematics.For example, most science students have mastered the basic knowledge of integral, but liberal arts students do not understand it, so they are very confused in the process of learning. There is a state of boredom and a serious lack of autonomy in learning.Compared with science students, especially students with a very good mathematical foundation, they feel that the learning content is too simple to arouse their interest in learning, and it also hinders the cultivation of autonomous learning ${ }^{[1]}$.

B. Students are more dependent on teachers

Because the traditional teaching has the deep-rooted influence, in the teaching process mainly teaches the way for the teacher. Students passively accept knowledge, students lack initiative, independent analysis and problem-solving ability.In the higher order teaching, students need to learn a lot of content, but also need to find a lot of information, so the collective discussion of learning activities and practical homework can not be implemented by the time limit. Students have no opportunity to express their inner feelings and put forward their opinions.

C. Problems arising in the teaching content, time and manner of higher mathematics

At this stage, the teaching materials focus on logic, application is not high. The application teaching material mainly regards the application as the main content teaching.However, in practical teaching, students lack enough understanding of knowledge, can not effectively use mathematical knowledge to solve the problems existing in reality, teachers do not fully understand the characteristics of students. This results in many situations in practical teaching.Due to time constraints in teaching, teachers can not impart knowledge to students more systematically. In addition, too much attention to gradual learning, resulting in students inert mood. This has a serious impact on the cultivation of students' autonomous learning ability, and the boring learning style causes students to be unable to better engage in learning ${ }^{[2]}$.

\section{Ways to Improve Students' Autonomous Learning Ability}

A. Creating a student-oriented campus environment and strengthening students' awareness of autonomous learning

Create a student-oriented campus environment to achieve teaching results. The knowledge level of college students is relatively high, and it has higher requirements for the realization of selfworth.Teachers should promote their own value according to the relevant policies of education, so as to stimulate their initiative in learning.For example: campus famous teacher lecture, student study organization and so on. Through time, it is shown that creating a good autonomous learning environment, organizing cooperative learning activities and creating a harmonious campus atmosphere play a positive role in enhancing students' learning consciousness. Teachers should understand 
the characteristics of each student and give full play to their great potential so as to mobilize the effectiveness of students' autonomous learning ${ }^{[3]}$.

B. Establishing a harmonious teacher-student relationship

In teaching, we need to break the traditional teacher-student relationship, that is, teachers-led, let students learn independently. In the process of students' learning, teachers are the organizers of learning, and at the same time act as mentors and counsellors.In learning, students are participants, controllers and beneficiaries of learning activities.For example, the subject of Application for innovative training Program for College Students, in terms of content selection and the effect conveyed, is designed by students, which to the greatest extent stimulates students' autonomy and creative spirit.As one of them, teachers give effective guidance to the problems in the design project. Therefore, autonomous learning is teacher-led, let students learn independently, so as to achieve the effect of learning.

C. Designing problem situations to arouse students' interest in autonomous learning

The educator Spencer said that "education should be pleasant, and all education should be fun ."So a successful math class requires a good start. In the process of the new class, the teacher cleverly designs the problem situation, and the students immerse themselves in the study and explore the mystery.Students have a strong interest in learning, will be involved in the state of autonomous learning ${ }^{[4]}$.For example, how the "Newton-Leibniz formula" proposition comes from, students will have a variety of questions, teachers can explain according to historical data:According to historical records 1, Newton and Leibniz almost at the same time this result, because they are in an independent working space, the time Newton earlier than Leibniz ten years, but the time Leibniz earlier than Newton three years.Later generations, in memory of them, named it "Newton-Leibniz formula ".According to historical records, Newton, as one of the first to study calculus, after Newton, the more in-depth study of calculus is Leibniz, which in the field of calculus.But at that time, Newton was much more famous in the academic field than Leibniz, plus its super prestige, so although they invented the formula at the same time, it was named Newton before, and Leibniz after.For example, the introduction of the concept of limit can be traced back to the three Kingdoms period, according to historical records: Liu Hui, as the greatest mathematician in the history of our country, was the first time he used to make a regular polygon in a circle, that is ," cutting a circle ". The equal points are cut out on the circumference, and then the regular polygon in the circle is obtained, its area is smaller than the circle area.Then the number of regular polygons is increased, and the area of the circle is increased. The more the number of edges, the more the area of the circle is reached. By expanding the segmentation infinitely, the real area value of the circle can be obtained.In this way, students can clearly define the concept of limit, let students understand these knowledge, not only can more in-depth understanding of mathematical knowledge, thus improving the ability of mathematical thinking, but also can stimulate the fun of students' autonomous learning.

D. Strengthen the guidance of autonomous learning and expand the channels for autonomous learning 
Teachers take various means to clarify students' reality and guide students to find their own value. Open curriculum system can promote students' autonomous learning ability. The higher education of our country pays attention to the specialty counterpart, the curriculum revolves around the specialty as the core, this kind of relatively monotonous education system, causes the talented person training pattern to be single, this hinders the student to study independently to some extent ${ }^{[5]}$. Therefore, innovating the curriculum system and opening up is the main channel to open up autonomous learning.Expand the scope of knowledge, can maximize the enthusiasm of students to learn independently. When the teacher explains the theorem, the student may have great interest in the mathematician who discovers the theorem.For example :" the beauty and reason of mathematics "," the story of mathematics "and so on, thus makes the argument for the theory research, then creates more ways for the autonomous learning. In addition, network technology has been widely used in students' learning. Students can acquire knowledge in various media, which fully stimulates students' thinking ability. Students choose their own learning path, so as to better enhance their own autonomous learning ability.

E. Developing students to have good learning motivation

Learning motivation is the main motive force to stimulate students to learn actively. As long as students have a strong learning motivation, they will think and find the best way to learn, and can make a clear learning plan for themselves.And can effectively grasp the best time to learn, overcome the difficulties encountered in learning, combined with their own situation to actively acquire knowledge. Therefore, the main characteristic of autonomous learning is that students mobilize their learning motivation from the bottom of their hearts.Learning motivation is a necessary prerequisite to enhance students' autonomous learning. In the process of higher mathematics teaching, teachers should not only teach textbook knowledge, but also understand the different characteristics of each student. It is necessary to effectively cultivate students' learning motivation.For example, in explaining mathematical knowledge, teachers can let students understand the beauty of mathematics, understand the relationship between higher mathematics and different subjects, and make them realize that higher mathematics is an auxiliary tool for other subjects.By designing mathematical situations to stimulate students' curiosity and discover the mystery of the mathematical world, and can feel the sense of achievement through learning mathematics, thus improving the ability of mathematics learning.Only with strong learning motivation, can students better mobilize the initiative of learning mathematics. Because learning motivation is spontaneous goal setting, teachers need to guide students to understand themselves correctly and to make correct evaluation of themselves. To improve students' subjective initiative, teachers can design different teaching schemes according to the different conditions of students, so that students can realize the mood of success stimulate students' autonomy in learning.

F. Correct students' bad habits and learning styles in a timely manner

It is a long-term process to cultivate students' autonomous learning ability. In this stage, teachers must understand and observe the students more, find out the bad study habits and learning methods in time, and correct them in time. Teachers should communicate with students in time to find out the 
problem and find out the solution. In view of common problems, such as copying homework, teachers need to make a stand, take measures to guide students, and take measures to correct them by means of rewards and punishments ${ }^{[6]}$.

\section{Conclusion}

To sum up, teachers need to pay attention to improving students' autonomous learning ability. Once a good habit is formed, it can make students' learning efficiency with half the effort. It is a long-term process to cultivate students' autonomous learning ability.Teachers need to explore more deeply. On the issue of cultivating college students' active learning, teachers need to analyze the inevitable relationship between college students' autonomous learning and educational methods from many aspects. And then create a more active learning atmosphere for college students.In the current educational environment with students as the main body, we must carry out the learning model with happy learning as the core content. In the process of new undergraduate higher mathematics teaching, teachers should actively cultivate students' autonomous learning ability, enhance students' enthusiasm for autonomous learning, promote the smooth development of teaching reform, and then improve the efficiency of higher mathematics teaching.

\section{Acknowledgement}

This work is supported in part by Application of virtual reality technology in Advanced Mathematics Teaching, Teaching reform project of Taishan University in 2018,201825

\section{References}

[1] Gou Min phosphorus. How to Guide Students to Self-Learning [J].] in Higher Mathematics Teaching modern communication ,2020, No.528(10) $\square 220-221$.

[2] Ren Ming, Yun Shiwei. Application of Microcourse in Advanced Mathematics Informatization Teaching [J].]; and Education and Teaching Forum ,2018(39):189-190.

[3] Yang Lirong. Cultivation of Self-Learning Ability of Middle School Students in Higher Mathematics Teaching [J].].1 Tomorrow ,2018,(21):285-285.

[4] Yang Xiaojie. Application of Microcourse in Teaching Practice under the J]. of Higher Mathematics Teaching Reform China Light Industry Education ,2018,(5):83-86.

[5] He Jie. The Application of Hybrid Teaching Model in Higher Mathematics Teaching Taking "Function Limit" as an example [J].Chinese and foreign exchanges 26(28):40-41.

[6] Jin Baoxia, Tian Xianzhen. Research and Application of SPOC Hybrid Teaching Model in”Advanced Mathematics “[J]; andKnowledge Guide ,2018,(19):132-133. 